\title{
CORRELATION OF BODY MASS INDEX WITH THYROID-STIMULATING HORMONES IN THYROID PATIENT
}

\author{
ANUPAM SHARMA ${ }^{1}$, SAVITA DEVII ${ }^{1}$, KAMALDEEP SINGH ${ }^{2}$, PRANAV KUMAR PRABHAKAR ${ }^{1 *}$ \\ ${ }^{1}$ Department of Medical Laboratory Sciences, Lovely Professional University, Phagwara - 144411, Punjab, India. ${ }^{2}$ Department of Medical \\ Laboratory Sciences and Biotechnology, CT Group of Institute, Shahpur, Jalandhar, Punjab, India. E-mail: pranav.16113@lpu.co.in
}

Received: 05 April 2018, Revised and Accepted: 11 July 2018

\section{ABSTRACT}

Objective: The present study was investigated to determine the correlation of body mass index (BMI) with thyroid-stimulating hormones (TSH) in thyroid patient.

Methods: The data which are used in this study were taken in Tagore Hospital and Heart Care Centre (Jalandhar). A total of 90 volunteers both males and females in the age group between 17 and 85 years were included in this study. The following information taken on pro forma such as age in years, height $(\mathrm{cm})$, weight $(\mathrm{kg})$, and history (including: Chief complaints, family thyroid history, blood pressure, temperature, and head and neck examination) from the subjects were collected. Serum T3, T4 and TSH test are performed by the use of instrument ADVIA Centaur@CP Immunoassay System (SIEMENS). The total data were divided into three groups named as: Subclinical hypothyroid (SH) ( $\mathrm{n}=30$ ), euthyroid ( $\mathrm{n}=57$ ), and hyperthyroid including only three patients, and according to age, weight $(\mathrm{kg})$, height $\left(\mathrm{m}^{2}\right)$, and BMI, the mean \pm standard deviation (S.D) values were calculated. The BMI is calculated with the formula given by the WHO.

Results: For correlation analysis, according to total male and female population in euthyroid group, the mean and SD values of TSH and BMI were calculated. Maximum values of T3 (4.7) and T4 (22.1) in hyperthyroid and TSH (9.9) in SH group were found. The high mean values of T3 (2.92) and T4 (18.46) in hyperthyroid and TSH (29.1) in SH group were observed. Low mean values of T3 (0.97) and T4 (7.7) in SH and low mean TSH (0.04) in hypothyroid group were noticed.

Conclusion: Based on the data analysis, it can interpreted that a poor positive correlation between TSH and BMI and poor negative correlation between TSH and BMI are associated in euthyroid subjects. It indicates that, when TSH increases, the BMI will also be increased in total and female euthyroid subjects.

Key words: Thyroid hormones, Thyroiditis, Hypothyroidism, Euthyroid, Subclinical hypothyroidism.

(c) 2018 The Authors. Published by Innovare Academic Sciences Pvt Ltd. This is an open access article under the CC BY license (http://creativecommons. org/licenses/by/4. 0/) DOI: http://dx.doi.org/10.22159/ajpcr.2018.v11s2.28580

\section{INTRODUCTION}

The thyroid is an endocrinal, butterfly-shaped, and biggest gland in the neck which makes and stores hormones that help in the regulation of blood pressure, heart rate, and body temperature and also help in the regulation of growth and rate of chemical reactions (metabolism) in the body. The thyroid gland made up from follicular cells which produce two major hormones of the thyroid gland - T3 (triiodothyronine) and T4 (tetraiodothyronine or thyroxine) and few parafollicular cells (C - cells) produces hormone called "Calcitonin" which helps in the regulation of calcium homeostasis [1-3]. Higher amount (80-95\%) of T4 is formed, but it is biologically less active, and $\mathrm{T} 3$ is found in less amount (about 5-20\%) biologically more active than T4 [4]. Thyroid gland cells have receptor site, thyroid-stimulating hormones (TSH) secreted by anterior pituitary linked with these receptors, and the cells stimulated to produce and release thyroid hormones. If more $\mathrm{T} 3$ and $\mathrm{T} 4$ are required to the body, then more amount of TSH is produced, and if less T4 and T3 are required, then small amount of TSH is produced by pituitary gland [5]. TSH regulates the iodide uptake by sodium/iodide symporters; the steps are necessary for normal thyroid hormone synthesis and secretion [6]. In circulation majority of $\mathrm{T} 4$ and $\mathrm{T} 3$ bound with carrier proteins, such as Thyroxine binding proteins (TBG), having higher affinity for $\mathrm{T} 4$, thyroxine binding prealbumin (transthyretin) and albumin, which helps in transportation [7]. Only a small fraction remains unbound known as free T3 (fT3) and free t4 (fT4) in the circulation, and when it reached into the required tissue, it enters inside the cells by unique transport channels and cytoplasm is the site where conversions of T4 to T3 take place, mainly in liver, pituitary gland, kidney, and peripheral tissue. Normally, about $0.03 \%$ T4 and $0.5 \%$ T3 were found in unbound form, and only free form has the ability to bind with specific hormone receptor in peripheral tissue [8].

Hypothyroidism, hyperthyroidism, thyroiditis, goiter, nodes, and tumor of thyroid gland are the common diseases which are related to thyroid gland [9]. Hypothyroidism is a clinical syndrome resulting from the deficiency of thyroid hormones which leads to slow down the metabolic processes [10]. The cases of thyroid failure were most commonly observed in women's and incidence is increased with age [11]. Autoimmune chronic lymphocytic thyroiditis is the most common cause of hypothyroidism in Australia. It is commonly seen in diabetic patients $[12,13]$. It is obesity like pathological condition, associated with lipid metabolism disorders, and leads to dyslipidemia (one of the major risk factors of coronary diseases) [14]. Hypothyroidism is associated with cardiovascular risk factors, and if remains untreated, it can lead to atherosclerosis [15]. Subclinical hypothyroidism (SH) is defined as abnormal condition which appears with mild elevated TSH level (5$10 \mathrm{mIU} / \mathrm{L}$ ), normal thyroid hormones concentration with no clinical signs and symptoms. It is estimated that $4.3-9 \%$ of general population was affected with SH $[16,17]$. Effect of SH is not well understood yet, but various studies reported that it is associated with high levels of lowdensity lipoprotein (LDL), total cholesterol (TC), and cardiovascular disease patients [18]. Among the childrens, autoimmune thyroiditis is the most common cause of $\mathrm{SH}$ and diagnosed by elevated levels of serum thyroid peroxidase. Overt hypothyroidism was diagnosed by decreased serum fT4 with increased TSH levels. Overt hypothyroidism 
is associated with hypercholesterolemia. Previous studies suggested that patients with overt hypothyroidism have more risk of developing atherosclerotic disease. The well-documented features of overt hypothyroidism are high levels of apolipoprotein B, LDL cholesterol, and total cholesterol $[19,20]$. Therefore, the catabolism of LDL and intermediate density lipoprotein is decreased because the activity of LDL receptors decreased and [21]. An elevated homocysteine level is a risk factor for cardiovascular disease (CVD), and its levels are reported to be increased in overt hypothyroidism. Hyperthyroidism also called thyrotoxicosis caused by the overproduction of thyroid hormones. The prevalence found more in women $(2 \%)$ than men $(0.2 \%)$, and $15 \%$ of cases of hyperthyroidism occurs in patient older than 60 years. In iodine-sufficient areas, the prevalence of overt hyperthyroidism is 2 per 1000 and subclinical hyperthyroidism is 6 per 1000 [22]. In general population, the incidence of hyperthyroidism is lower $(2.2 \%)$ as compared to hypothyroidism [23]. The symptoms of hyperthyroidism vary according to the age, amount of $\mathrm{T} 3$ and $\mathrm{T} 4$ you have, and how long your thyroid gland produces excess T3 and T4. It mainly appears with symptoms of sympathetic nervous system. Young patients may suffer with anxiety, tremor, and hyperactivity, and older patients have more cardiovascular symptoms including dyspnea, atrial fibrillation, and weight loss [24].

\section{METHODS}

The present study was carried out in Tagore Hospital and Heart Care Center (Jalandhar). A total of 90 volunteers both males and females in the age group between 17 and 85 years were included in this study. Age in years, height $(\mathrm{cm})$, weight $(\mathrm{kg})$, and history (including chief complaints, family thyroid history, blood pressure, temperature, and head and neck examination) from the subjects were collected.

\section{Exclusion criteria}

Smokers and alcoholic were excluded from the study.

\section{Blood sample collection}

From all the subjects who came for the determination of thyroid profile, the blood samples with record of age and sex were collected. By venepuncture method, approximately $5 \mathrm{ml}$ blood was collected in plain vial from all subjects, and after centrifugation, the serum sample was analyzed for quantitative estimation of T3, T4, and TSH levels. The estimation of T3, T4, and TSH in human Serum was done by Autoanalyzer named as "ADVIA Centaur@CP Immunoassay System" (SIEMENS) based on "Sandwich principle."

\section{Reference Range:}

The reference range is as follows:

T3 $-0.60-1.81 \mathrm{ng} / \mathrm{ml}$.

$\mathrm{T} 4-3.20-12.6 \mathrm{ug} / \mathrm{ml}$

TSH - 0.35-5.0 uIU/ml.

\section{Anthropometrical measurements}

An instrument named as stadiometer was used to measure height (m) and standard weighing machine used for weight. The body mass index (BMI) was calculated using formula.

$$
\text { Body mass index }(\mathrm{BMI})=\frac{\text { Weight }(\mathrm{kg})}{\operatorname{Height}^{2}\left(\mathrm{~m}^{2}\right)}
$$

BMI is classified as follows: $<18.5$ - underweight, 18.5-24.9 - normal weights, $>25.0$ - overweight, $>30.0$ - overweight, 30.0-34.9 - obese Class I, 35.0-39.9 - obese Class II, and $>40.0$ - obese Class III (according to the WHO).

\section{Biochemical analysis}

Thyroid profile assay (T3, T4, and TSH) was performed using instrument - ADVIA Centaur@CP Immunoassay System (SIEMENS).
Principle of ADVIA Centaur@CP immunoassay system (SIEMENS)

Chemiluminescence is a chemical reaction that emits energy in the form of light, and when used with immunoassay technique, the light produced by the reaction indicates the amount of analyte in a sample.

In CLIA, microplate luminometers are used which give a sensitive, easy, and alternative to conventional colorimetric methods (ELISA). The technique (ELISA) is based on colorimetric reactions of chromogenic substrates (e.g., TMB) and label enzymes. CLIA provides high sensitivity over the conventional colorimetric methods in terms of less incubation time and the use of stopping reagents. The CLIA involves a horseradish peroxidase-labeled antibody or antigen and a mixture of chemiluminescent substrate, hydrogen peroxide, and enhancers. CLIA kits are designed to detect chemiluminescent reactions. The method is highly sensitive for T3, T4, and TSH estimation.

\section{RESULTS}

The present study was conducted on a total of 90 individuals. Both males and females in the age group between 17 and 81 years were included in this study. First, the total data were divided into three groups named as follows: Subclinical hypothyroid $(n=30)$, euthyroid $(n=57)$, and hyperthyroid including only three patients, and according to age, weight $(\mathrm{kg})$, height $\left(\mathrm{m}^{2}\right)$, and $\mathrm{BMI}$, and the mean \pm S.D values were calculated.

As a comparison between three groups, minimum values of T3 $(0.60)$ in euthyroid, T4 (4.1) in SH, and TSH (0.01) in hyperthyroid were observed. Maximum values of T3 (4.7) and T4 (22.1) in hyperthyroid and TSH (9.9) in SH group were found. The high mean values of T3 (2.92) and T4 (18.46) in hyperthyroid and TSH (29.1) in SH group were observed. Low mean values of T3 (0.97) and T4 (7.7) in SH and low mean TSH (0.04) in hypothyroid group were noticed.

For correlation analysis, according to total, male, and female population in euthyroid group, the mean and standard deviation values of TSH and BMI were calculated and placed into the Tables 1-3. Correlation coefficient ( $\mathrm{r}$ value) for total, male, and female were calculated in Microsoft Office Excel Worksheet using (Data Analysis) correlation formula. The correlation coefficient $(\mathrm{r}-$ value) lies from -1 to +1 .

Tables 4 and 5 show poor positive relationship between TSH and BMI in euthyroid (total) that means that, if one variable increases, the other variable also increases, or if one decreases, other will also decrease. In males, poor negative correlation (means one variable increases and other variable decreases or vice versa) and in females poor positive relation were observed in euthyroid group. In SH group, poor negative correlation was found in total, male, and female population.

\section{DISCUSSION}

The present study was undertaken to find the association between TSH and BMI in subclinical hypothyroid patients and euthyroid individuals. This study includes a total of 90 individuals that categorized into three groups (as euthyroid, subclinical hypothyroid, and hyperthyroid) according to their $\mathrm{T} 3, \mathrm{~T} 4$, and TSH levels. The normal range for thyroid profile is as follows:

$\mathrm{T} 3-0.60-1.80 \mathrm{ng} / \mathrm{ml}$.

$\mathrm{T} 4-3.20-12.6 \mathrm{ug} / \mathrm{ml}$

TSH - 0.35-5.0.

In total, euthyroid subjects include 57 numbers, subclinical hypothyroid include 30, and hyperthyroid include only 3 patients. In our study, we found a high prevalence of thyroid diseases in females $(n=66 \%)$ than males $(n=24 \%)$. Various previous studies observed that thyroid hormones can affect the body weight by altering the basal metabolic rate. Some studies show decreased thyroid functions associated with weight gain or obesity, and other analysis shows no relation with this regard. The link between body weight and TSH level is especially attractive. 
Table 1: The general data with values (mean \pm S.D) of age, weight $(\mathrm{kg})$, height $\left(\mathrm{m}^{2}\right)$, and BMI in three groups

\begin{tabular}{llll}
\hline Parameter & Subclinical hypothyroid $(\mathbf{n}=\mathbf{3 0})$ & Euthyroid $(\mathbf{n}=\mathbf{5 7})$ & Hyperthyroid $(\mathbf{n}=\mathbf{3})$ \\
\hline Age $($ years $)$ & $48.6 \pm 15.8$ & $52.0 \pm 12.5$ & $47.3 \pm 11.0$ \\
Weight $(\mathrm{Kg})$ & $74.3 \pm 16.7$ & $70.4 \pm 11.5$ & $73.3 \pm 2.8$ \\
Height $\left(\mathrm{m}^{2}\right)$ & $2.67 \pm 16.7$ & $2.68 \pm 0.3$ & $2.72 \pm 0.2$ \\
BMI $\left(\mathrm{Kg} / \mathrm{m}^{2}\right)$ & $27.7 \pm 5.8$ & $26.3 \pm 4.6$ & $27.0 \pm 2.9$ \\
\hline
\end{tabular}

The values (mean \pm S.D) of various parameters including thyroid profile, BMI, and weight were distributed according to the age groups. BMI: Body mass index

Table 2: The status of various parameters including thyroid profile (T3, T4, and TSH), BMI, and weight according to different age groups

\begin{tabular}{lllllll}
\hline Age group (years) & $\mathbf{n}$ & T3 $(\mathbf{n g} / \mathbf{m l})$ & T4 $(\mathbf{u g} / \mathbf{m l})$ & TSH (uIU/ml) & BMI (m) & Weight (kg) \\
\hline $17-30$ & 7 & $1.13 \pm 0.37$ & $7.31 \pm 2.66$ & $5.28 \pm 3.36$ & $24.32 \pm 4.83$ & $65.71 \pm 11.94$ \\
$31-40$ & 13 & $1.24 \pm 1.06$ & $8.96 \pm 4.46$ & $4.40 \pm 3.07$ & $26.8 \pm 4.68$ & $70.46 \pm 16.09$ \\
$41-50$ & 25 & $1.05 \pm 0.34$ & $8.77 \pm 2.77$ & $3.66 \pm 2.77$ & $28.81 \pm 5.72$ & $75.6 \pm 14.73$ \\
$51-60$ & 23 & $1.11 \pm 0.31$ & $9.58 \pm 2.89$ & $3.20 \pm 2.04$ & $26.27 \pm 4.63$ & $72.21 \pm 13.29$ \\
$61-70$ & 18 & $1.04 \pm 0.34$ & $8.35 \pm 2.27$ & $3.79 \pm 2.76$ & $26.51 \pm 4.94$ & $69.72 \pm 10.51$ \\
$>70$ & 4 & $0.97 \pm 0.20$ & $9.45 \pm 1.87$ & $7.59 \pm 2.29$ & $23.8 \pm 0.96$ & $70.5 \pm 7.72$ \\
\hline
\end{tabular}

BMI: Body mass index, TSH: Thyroid-stimulating hormones

Table 3: The minimum, maximum, average, and SD values of thyroid profile (T3, T4, and TSH) in all three groups (S.H, euthyroid, and Hyperthyroid)

\begin{tabular}{|c|c|c|c|c|c|c|c|c|c|}
\hline \multirow[t]{2}{*}{ Parameter } & \multicolumn{3}{|l|}{ SH $(n=30)$} & \multicolumn{3}{|c|}{ Euthyroid (n=57) } & \multicolumn{3}{|c|}{ Hyperthyroid $(n=03)$} \\
\hline & T3 (ng/ml) & $\mathrm{T} 4(\mathrm{ug} / \mathrm{ml})$ & TSH (uIU/ml) & T3 (ng/ml) & $\mathrm{T} 4(\mathrm{ug} / \mathrm{ml})$ & $\begin{array}{l}\text { TSH (uIU/ } \\
\text { ml) }\end{array}$ & T3 (ng/ml) & $\begin{array}{l}\text { T4 (ug/ } \\
\mathrm{ml})\end{array}$ & TSH (uIU/ml) \\
\hline Min & 0.66 & 0.41 & 5.03 & 0.60 & 4.4 & 0.54 & 1.99 & 15.1 & 0.01 \\
\hline Max & 1.63 & 12.5 & 9.9 & 1.86 & 12.5 & 4.94 & 4.7 & 22.1 & 0.11 \\
\hline Mean & 0.97 & 7.7 & 7.39 & 1.07 & 8.89 & 2.39 & 2.92 & 18.46 & 0.04 \\
\hline SD & 0.25 & 2.56 & 1.58 & 0.29 & 2.14 & 1.15 & 1.53 & 3.50 & 0.05 \\
\hline
\end{tabular}

SH: Subclinical hypothyroid, SD: Standard deviation

Table 4: The correlation of TSH and BMI in euthyroid subjects

\begin{tabular}{llllll}
\hline Sex & $\mathbf{n}$ & TSH $(\mathbf{U l u} / \mathbf{m l}$ & $\left.\mathbf{B M I} \mathbf{( K g} / \mathbf{m}^{2}\right)$ & $\mathbf{r}$ value & Correlation \\
\hline Total & 57 & $2.39 \pm 1.51$ & $26.37 \pm 4.67$ & 0.14 & Poor positive \\
Male & 14 & $2.48 \pm 1.35$ & $26.01 \pm 4.29$ & -0.05 & Poor negative \\
Female & 43 & $2.36 \pm 1.09$ & $26.48 \pm 4.82$ & 0.21 & Poor positive \\
\hline
\end{tabular}

BMI: Body mass index, TSH: Thyroid-stimulating hormones

Table 5: The correlation of TSH and BMI in subclinical hypothyroid patients

\begin{tabular}{llllll}
\hline Sex & $\mathbf{n}$ & TSH $(\mathbf{U l u} / \mathbf{m l}$ & BMI $\left(\mathbf{K g} / \mathbf{m}^{2}\right)$ & r value & Correlation \\
\hline Total & 30 & $7.39 \pm 1.58$ & $27.71 \pm 5.86$ & -0.05 & Poor negative \\
Male & 9 & $7.36 \pm 1.64$ & $26.95 \pm 3.90$ & -0.27 & Poor negative \\
Female & 21 & $7.40 \pm 1.54$ & $28.04 \pm 6.58$ & -0.01 & Poor negative \\
\hline
\end{tabular}

BMI: Body mass index, TSH: Thyroid-stimulating hormones

In previous studies, it was found that association between TSH and BMI could be altered by smoking, but in recent studies, a positive correlation within BMI and TSH was observed in smokers. A study conducted by Knudsen et al. (2005) noticed that little changes in thyroid function are associated with alteration in BMI, but the exact mechanism about this association is not clear. The obesity is defined by BMI $(>25)$, and most of the patients were found to obese who came for the assessment of thyroid functions in the hospital.

Obesity is appeared with alterations in lipid parameters which further leads to CVD. The decrease functions of thyroid gland are related to obesity, and it was suggested that there must be association lying between lipid profile and thyroid hormones. Various studies were conducted to find the relationship between TSH and lipid profile but yet they do not observed any clear relationship.
A recent study performed by Laway et al. in 2014 was to evaluate the variations in lipid parameters between subclinical hypothyroid, and normal individuals were observed the 39 elevated levels of TC, triglycerides, and very low-density lipoprotein (VLDL) in patients with SH. No relationship was observed between HDL and TSH.

In the present study, the poor positive correlation ( $\mathrm{r}$ value - 0.14 ) between TSH and BMI was observed in total euthyroid subjects. A poor negative association was observed between TSH and BMI in males and poor positive ( $r$ value - 0.21) relationship was observed in euthyroid females (shows in Table 4). Suganty et al. (2011) were reported that there was a significant positive correlation between serum TSH and BMI in euthyroid females. Deiz et al. also noticed a significant correlation between TSH and BMI in euthyroid subjects. They conclude that TSH level significantly increased with weight.

In $\mathrm{SH}$ patients (total, male, and female), poor negative correlation was observed between TSH and BMI(Table 5). This indicates that the vice versa relationship lies between TSH and BMI in SH patients. The SH also called mild thyroid failure is defined as a normal thyroid hormones but mildly elevated TSH $(5-10 \mathrm{uIU} / \mathrm{ml})$ with no or mild sign and symptoms. The mild symptoms include weight gain, memory problems, and cold intolerance. In the present study, the prevalence of weight gain, less sleep, and joint pain observed more in SH patients.

Patients with SH have a higher risk of CVD then euthyroid. The occurrence of $\mathrm{SH}$ was found significantly higher in female population. The information about "correlation between TSH and BMI in SH patients" is very less or not well understood. Prasad et al. in 2013 observed a statistically significant difference between male and female patients with SH. They conclude that the TSH levels were significantly higher in morbidly obese female's patients than in males.

The exact mechanism behind the increased TSH in obese person not clears properly and it is more difficult to find mild thyroid failure in obese persons. In obese adults and children's, elevated TSH appeared 
with enlargement of thyroid gland and hypoechogenicity. Diagnosis of hypothyroidism not only evaluated by ultrasound but also the proper diagnosis requires blood test with physical examinations.

The hypothyroidism is associated with weight gain or obesity which is the major risk factor for diabetes. Found by various researches that patients with diabetes may have abnormal thyroid functions. A study shows prevalence $18.3 \%$ of SH in patients with type 2 diabetes mellitus. The prevalence was found more in patients with age more than 50 years.

\section{CONCLUSION}

The thyroid hormones play various essential roles in our body, and they are essential for normal body functions. They were required to normal regulation of myocardial infarction, pulmonary ventilation, energy homoeostasis, vascular tone, water and electrolyte balance also helps in normal function of the CNS

Various studies were performed to find the association between TSH and BMI and each study gives a different finding in their study. Based on the data analysis, it can interpreted that a poor positive correlation between TSH and BMI and poor negative correlation between TSH and BMI are associated in euthyroid subjects. It indicates that, when TSH increases, the BMI will also be increased in total and female euthyroid subjects. Inverse or poor negative correlation was observed within TSH and BMI in patients with SH.

In the future, further studies regarding "correlation between BMI and TSH" will defiantly add an account in the previous study. Therefore, from the literature available and statistical analysis of the data, it is accepted and state as there is a positive correlation associated between BMI and TSH in euthyroid subjects (total and female).

\section{REFERENCES}

1. Tortora GJ, Derrickson BH. Principles of Anatomy and Physiology. $12^{\text {th }}$ ed., Vol. 1. Hoboken, NJ: John Wiley \& Sons; 2009. p. 658-9.

2. Peeters RP. Regulation of Thyroid Hormone Bioactivity in Health and Disease; 2005.

3. Surks MI, Ortiz E, Daniels GH, Sawin CT, Col NF, Cobin RH, et al. Subclinical thyroid disease: Scientific review and guidelines for diagnosis and management. J Am Med Assoc 2004;291:228-38.

4. Surks MI, Schadlow AR, Stock JM, Oppenheimer JH. Determination of iodothyronine absorption and conversion of L-thyroxine (T4) to L-triiodothyronine (T3) using turnover rate techniques. J Clin Invest 1973:52:805-11.

5. Koumourou R, Hanner R. Running on Empty Hypothyroidism; Introduction to an Underactive Thyroid Gland. Dandenong, Australia: GN \& EJ Ridgway; 2004. p. 41-2.

6. Brent GA, Koenig RJ. Thyroid and antithyroid drugs. In: Brunton L,
Chabner B, Knollman B, editors. Goodman and Gilman's The Pharmacological Basis of Therapeutics. 12 ${ }^{\text {th }}$ ed. New York, USA: McGraw-Hill Professional; 2002, 2010. p. 1129-61.

7. Bello F, Bakari AG. Hypothyroidism in adults: A review and recent advances in management. J Diabetes Endocrinol 2012;3:57-69.

8. The National Academy of Clinical Biochemistry. Standards of Laboratory Practice. Laboratory Support for the Diagnosis and Monitoring of Thyroid Disease. American Association of Clinical Chemistry; 1996. p. 1-64.

9. Komarica $\mathrm{EB}$, Beciragic $\mathrm{A}$. The importance of $\mathrm{HbA} 1 \mathrm{c}$ control in patients with subclinical hypothyroidism. Mater Soc Med 2012;24:212-9.

10. Greenspan FS. The thyroid gland. In: Greenspan FS, Gardner DG, editors. Basic and Clinical Endocrinology. $7^{\text {th }}$ ed. New York: The McGraw-Hill Companies; 2004. p. 215-94.

11. Rizos CV, Elisaf MS, Liberopoulos EN. Effects of thyroid dysfunction on lipid profile. Open Cardiovasc Med J 2011;5:76-84.

12. Proces S, Delgrange E, Vander Borght TV, Jamart J, Donckier JE. Minor alterations in thyroid-function tests associated with diabetes mellitus and obesity in outpatients without known thyroid illness. Acta Clin Belg 2001;56:86-90.

13. Michalek AM, Mahoney MC, Calebaugh D. Hypothyroidism and diabetes mellitus in an American Indian population. J Fam Pract 2000;49:638-40

14. Helfand M. Screening for subclinical thyroid dysfunction in nonpregnant adults: A summary of the evidence for the U.S. preventive services task force. Ann Intern Med 2004;140:128-41.

15. Shilpashree MK, Ravi BV, Vedavathi. Serum lipoprotein (a) and lipid profile in hypothyroidism. J Clin Biomed Sci 2014;4:235-9.

16. Gwinup G, Morton E. The high lying thyroid: A cause of pseudo goiter. J Clin Endocrinol Metab 1975;40:37-42.

17. Jain G, Marwaha TS, Khurana A, Dhoat PS. Prevalence of thyroid disorders in patients of Type 2 diabetes mellitus. Indian J Med Dent Sci 2013;2:48-52.

18. Canaris GJ, Manowitz NR, Mayor G, Ridgway EC. The Colorado thyroid disease sprevalence study. Arch Intern Med 2000;160:526-34.

19. Jung CH, Sung KC, Shin HS, Rhee EJ, Lee WY, Kim BS, et al. Thyroid dysfunction and their relation to cardiovascular risk factors such as lipid profile, hsCRP, and waist hip ratio in Korea. Korean J Intern Med 2003;18:146-53.

20. Packard CJ, O'Reilly DS, Caslake MJ, McMahon AD, Ford I, Cooney J, et al. Lipoprotein-associated phospholipase A2 as an independent predictor of coronary heart disease. West of Scotland coronary prevention study group. N Engl J Med 2000;343:1148-55

21. Weetman AP, McGregor AM. Autoimmune thyroid disease: Developments in our understanding. Endocr Rev 1984;5:309-55.

22. Mariotti S, Caturegli P, Piccolo P, Barbesino G, Pinchera A. Anti-thyroid peroxidase autoantibodies in thyroid diseases. J Clin Endocrinol Metab 1990;71:661-9.

23. Nordyke RA, Gilbert FI Jr, Miyamoto LA, Fleury KA. The superiority of antimicrosomal over an-tithyroglobulin antibodies for detecting Hashimoto's thyroiditis. Arch Intern Med 1993;153:862-5.

24. Surks MI, Ocampo E. Subclinical thyroid disease. Am J Med 1996;100:217-23. 